\title{
ВОЗМОЖНА ЛИ СЕКУЛЯРИЗАЦИЯ ИСЛАМА? (Взгляд на трансформации религиозности в контексте глобализации)
}

\author{
Хлопкова О. В., Клементьев А. С.
}

Анализируются соииальные, экономические, политические и иные факторы секуляризации и десекуляризации современного исламского общества. Особое внимание в статье уделяется причинам и особенностям политизачии ислама как способа противостояния процессу глобализации, обостряющего комплекс сочиальных, экономических и политических проблем исламского мира. Подчеркивается роль религии как средства определения цивилизачионной идентичности в условиях размывания культурных и государственных гранич. В рамках статьи трансформачии религиозности рассматриваются в контексте глобализачии и вестернизачии мусульманского мира.

Ключевые слова: секуляризация, десекуляризация, глобализация, исламский фундаментализм, исламизм.

The social, economic, political and other factors of secularization and desecularization of the modern Islamic society are analyzed. The causes and peculiarities of the politicization of Islam exposed to the influence of globalization are in the focus of the paper. Globalization is in charge of many social, economic and political problems of the Islamic world. The role of religion in the formation of civilizational identity under conditions of erosion of cultural and state borders is discussed. Westernization and globalization of the Muslim world are analyzed in the context of religion issues and transformations.

Keywords: secularization, desecularization, globalization, Islamic fundamentalism, Islamism.

Трансформации религиозности в истории человечества последних столетий были тесно связаны с феноменом секуляризации. Вместе с тем сам процесс секуляризации далеко не очевиден и вызывает множество споров: есть ли он вообще, действительно ли религия утрачивает свои позиции в обществе или только трансформируется в новых социальных условиях?

Теориями секуляризации называют «социологические концепции, объясняющие освобождение общества и различных его сфер и групп от религии» [Угринович 1990: 306]. И хотя к 90-м гг. ХХ в. в научном дискурсе установился консенсус относительно понимания сути явления секуляризации, под которой признается процесс утраты религией своей социальной значимости, на индивидуальном

\footnotetext{
* Хлопкова Оксана Васильевна - к. ф. н., доцент кафедры социологии и управления Московского автомобильно-дорожного государственного технического университета (МАДИ-ГТУ) Российской Федерации. E-mail: Oksana-hlopkova@mail.ru.

Клементьев Александр Станиславович - к. ю. н., ведущий научный сотрудник научно-исследовательского центра Академии управления Министерства внутренних дел Российской Федерации (АУ МВД России). E-mail: alex_klem@list.ru.
} 
уровне религия может оставаться значимой ценностью и мотивирующим фактором [Хлопкова 2013б: 19].

Тем не менее в связи с тем, что большинство теорий секуляризации являются продуктом западного общества и основываются на опыте западных стран, серьезной проблемой для объяснения данными теориями становятся процессы, происходящие в мусульманских странах, опыт которых во многом противоречит секулярным тенденциям: религия продолжает играть в жизни общества и государства огромную роль, выступая движущей силой политических, социальных, экономических и культурных процессов. Особую актуальность данная проблема приобрела после появления «исламистских проектов», в частности «Исламского государства»**.

\section{Секуляризация vs глобализация}

В настоящее время не вызывает сомнения, что глобализация не только трансформирует экономические и политические отношения между государствами, но затрагивает и иные сферы, в том числе религиозную. Так, возникает вопрос о взаимовлиянии секуляризации и глобализации.

С одной стороны, секуляризация оказывает самое непосредственное влияние на процесс международной интеграции, снижая уровень конфликтности в отдельных регионах либо, наоборот, обостряя социальные противоречия. Благодаря распространению информационных технологий, достижений культуры и науки, интенсификации миграционных потоков глобализация выступает проводником секулярных тенденций и одновременно способствует росту религиозности. Кроме того, смешение религий и культурных традиций в ходе глобализации порождает новые культы и новые формы религиозности [Хлопкова 2013a: 218]. Ярким примером подобных эклектичных религиозных культов стало учение Чандра Мохан Джеина, известного также как Бхагван Шри Раджниш или Ошо. Возникшее в 1970-е гг. и получившее сегодня широкое распространение во всем мире учение Ошо представляет собой хаотичную мозаику идей и практик буддизма, йоги, даосизма, христианства, греческой философии, суфизма, тибетских традиций, европейской психологии, хасидизма и других духовных течений, а также собственных взглядов Чандра Мохан Джеина [Григорьева 2002: 186-187].

С другой стороны, глобализация сама способствует распространению секулярных тенденций в иные культурные социосистемы. Так, процессы секуляризации можно было наблюдать и в исламских странах в ходе начавшегося в XX в. процесса диалога, взаимопроникновения и взаимопонимания двух культур - исламской и христианской. В мусульманскую среду стали проникать как идеи и образ жизни современного западного общества, так и те проблемы, с которыми сталкиваются христианские деноминации. Таким образом, глобализация ведет к большей открытости, модернизации, либерализации, научно-техническому развитию, культурному обогащению исламского мира, его интеграции в мировое пространство.

\section{Десекуляризация исламского мира: основные причины}

Вместе с тем развитие событий в последние годы в ряде мусульманских стран приводит к мысли о том, что ислам как религиозная система менее подвержен

\footnotetext{
** Террористическая организация, запрещенная на территории РФ. - Прим. ред.
} 
секулярным тенденциям. Устойчивость позиций ислама в современном мире определяется комплексом причин, среди которых особенности исламского вероучения занимают важное, но не главное место. Основными причинами, которые обеспечивают высокий уровень религиозности населения в мусульманских странах, являются:

1. Институциональные причины. Низкий уровень секуляризации исламских стран в определенной степени может быть объяснен такой особенностью ислама, как отсутствие в нем института церкви, разделения на светское и духовное. Ислам по сравнению с другими религиями глубже проникает в социально-политический организм общества: он с начала своего зарождения выступал в качестве регулирующего фактора всех важнейших функций в жизни общества. В обыденном сознании мусульманских народов ислам занимает универсальное место [Мансуров 2007]. Он фактически является не только религией, но и политикой, правом, этикой, образом жизни, то есть аккумулирует в себе практически все. Вследствие этого влияние религии на общественную и частную жизнь в мусульманских странах значительно сильнее, нежели в тех государствах, в которых правовые и экономические системы не зависят от религии и церкви.

2. Социально-экономические причины. Среди исследователей отсутствует единое мнение о том, как взаимосвязаны социально-экономические условия жизни и уровень религиозности населения. Во многом это связано как со сложностью исследуемого вопроса, невозможностью учета всех показателей и факторов, проблемами в установлении причинно-следственных связей, так и с препятствиями политического и морально-этического характера. Так, наличие корреляционной связи между уровнем социального благополучия общества и уровнем религиозности его населения не означает, что именно социально-экономическое неблагополучие является причиной высокого уровня религиозности, а не наоборот. Кроме того, в ряде стран, в которых религия является государственной идеологией (прежде всего мусульманских) или играет важную роль в социальных отношениях, публичный отказ от религии может вызвать общественное осуждение и даже меры наказания (вплоть до физического насилия).

Тем не менее в ряде исследований доказывается наличие определенной корреляции между уровнем религиозности населения и социально-экономическим благополучием. Так, Грегори Пол, проанализировав социально благополучные государства первого мира (в выборку вошли 17 стран с населением свыше 4 млн человек), пришел к выводу о том, что в высокоразвитых странах уровень общественного благополучия коррелирует с уровнем нерелигиозности или светскости. Им была выявлена положительная связь религиозности и таких показателей, как детская смертность, заболеваемость гонореей и сифилисом, количество абортов несовершеннолетних, уровень имущественного неравенства и отрицательная связь с продолжительностью жизни. В соответствии с результатами исследования Грегори Пола между религиозностью и общественным благополучием существует корреляция, при этом зависимой переменной является религиозность: то есть чем ниже уровень общественного благополучия, тем выше религиозность населения [Gregory 2009: 398-441].

Исследование американского социолога Жоржа Деламонтаня, в котором изучались признаки социально-экономического неблагополучия и их связь с религиозностью на примере отдельных штатов США, отчасти подтвердило выводы Грегори Пола, однако показало, что уровень религиозности в различных штатах 
сильнее коррелирует с уровнем образования и доходом, а также с числом афроамериканцев, чем с «показателями благополучия» (смертность, продолжительность жизни и т. д.). То есть религиозность также зависит от показателей социального неравенства [Delamontagne 2010: 617-657].

Проведенный для 47 стран на основании индекса религиозности Гэллапа (2012 г.) [Global...] и коэффициента Джини (2012 г.) [GINI...] (демонстрирует неравенство в распределении доходов) корреляционный анализ показал наличие умеренной связи между уровнем религиозности и уровнем социального расслоения (коэффициент Пирсона равен 0,44). Необходимо учитывать, что ряд государств в выборке относились к посткоммунистическим государствам, уровень религиозности в которых ниже, что обусловлено длительным господством атеистической идеологии. В связи с отсутствием верифицируемых данных по большинству стран, в которых превалирует исламское население, невозможно выявить корреляционную связь социального неравенства и уровня религиозности исключительно для данных государств. Тем не менее данные исследований и корреляционного анализа позволяют говорить о репрезентативности выводов и для указанных стран. Таким образом, уровень религиозности тем выше, чем выше уровень социального неравенства, а также социально-экономического неблагополучия.

Кроме того, регион, в котором находятся мусульманские государства, характеризуется многочисленными межгосударственными и межконфессиональными конфликтами. Все это порождает ощущение социальной опасности и напряженности. Так, Р. Инглхарт выделяет такой фактор религиозности, как «экзистенциальная безопасность». Безопасность как отсутствие рисков и опасностей очень важна для самочувствия человека, и, как считает исследователь, отсутствие такой безопасности является ключевым фактором для религиозности. Соответственно, чем выше уровень ощущения гражданином своей безопасности, тем ниже уровень религиозности, тем сильнее разрушаются религиозные ценности, верования и практики. «...Эрозия религиозных ценностей, верований и практик обусловлена длительными изменениями в экзистенциальной безопасности, связанными с человеческим развитием и социоэкономическим равенством», - пишет Р. Инглхарт [Inglehart, Norris 2004]. Жители бедных стран часто оказываются крайне уязвимыми перед непредсказуемыми рисками. По мере развития бедных аграрных экономик до уровня современных индустриальных обществ, а затем и превращения их в более богатые постиндустриальные общества происходит улучшение основных условий человеческой безопасности. Именно состоянием в сфере личной безопасности, понимаемой в широком смысле, Инглхарт объясняет современные различия в религиозности разных обществ. Соответственно, в длительной перспективе в результате процесса человеческого развития (который должен усиливать ощущение экзистенциальной безопасности) значимость религии в человеческой жизни будет постепенно уменьшаться [Ibid.].

Исследование, проведенное Институтом Гэллапа в 2008 г., подтвердило гипотезу Р. Инглхарта. Опросы Института Гэллапа в 32 странах со среднегодовым доходом до 2000 долларов показали, что религиозность в жизни населения данных государств является значимым фактором социального самочувствия. Так, респонденты, которые говорили о том, что религия играет важную роль в их жизни, с большей вероятностью испытывали позитивные чувства (радость, удовольствие) и более позитивно оценивали вчерашний и завтрашний день, чем те, кто не придавал религии важного значения. В странах с доходом выше 25000 долларов 
в год подобная разница оказалась минимальна. Более того, о важности религии в жизни в экономически развитых странах заявило всего $44 \%$ респондентов, в то время как в экономически неблагополучных - 92 \% [Crabtree, Pelham].

Глобализационные процессы, связанные с трансформацией сообществ, а также ростом их взаимозависимости и усилением потоков людей, информации, денег и оружия, приводят к росту социального напряжения и обуславливают обращение людей к религии как к понятной системе вечных ценностей. Так, сторонниками фундаментального ислама часто становятся мигранты, попавшие в инокультурную среду. В иноэтничном и инокультурном обществе многие мигранты чувствуют себя отторгнутыми, испытывают проблемы в коммуникации с местным сообществом, могут подвергаться унижению, дискриминации по этническому и религиозному признакам, а часто и физическому насилию. Все это повышает уровень внутренней тревожности человека, ощущение нестабильности, желание социальной справедливости и равенства.

3. Политико-идеологические причины. Попытки модернизации государства по примеру стран Запада или СССР не всегда приносили ожидаемые результаты, обостряя и без того глубокие социальные противоречия. Распад социалистического лагеря и крах коммунистической идеологии в конце XX в. разрушили идеологическую антиномию либерализма и социализма, в результате чего значительная часть человечества, не принимающая идеи либерализма, оказалась в ситуации утраты идей «торжества справедливости на земле» [Сейлова 2008].

Разочарованием оборачивались и поиски национальных путей развития, в том числе основанные на секулярных идеологиях. Так, сегодня со всей очевидностью можно констатировать кризис национального государства в некоторых арабских странах, который был предопределен целым комплексом причин: незавершенностью процесса нациостроительства, фрагментированностью общества внутри арабских государств, дефицитом легитимности государственной власти, противоречиями институционального развития, трансформацией и нарушением каналов коммуникации между политической элитой и обществом, кризисом секулярных идеологий, которые не смогли исполнить того, что обещали, и др. [Кузнецов, Салем]. Говоря о незавершенности процесса нациестроительства в некоторых исламских странах, стоит вспомнить и фактор «искусственности» формирования государственных границ. Объединение разнородных исторических областей в рамках одного государства, проведенное колонизаторами, часто является одной из причин политической нестабильности некоторых государств (например, Ливия была образована путем объединения исторических областей Киренаики, Триполитании и Феццана).

Как следствие, кризис государственного устройства, социально-экономического и идейно-политического развития обострил поиск простых и удобных схем объяснения социальной реальности, а также предлагающих четкие и «действенные» методы изменения сложившейся ситуации. Подобным выходом для многих стало обращение к исламской альтернативе, выражающейся в замене несостоятельных правителей и создании исламского государства, зиждившегося на понятных и простых идеях социальной справедливости.

Ряд авторов утверждает, что причиной десекуляризации в ряде стран, которые, как казалось, перешли к западной модели государства (Иран, Пакистан, Афганистан и др.), является архаизация социальных отношений, которая развивается в векторе, противоположном глобализации. Однако вестернизация и модерниза- 
ция отношений в этих государствах затрагивали, как правило, городскую прослойку. Большая же часть населения модернизацией затронута не была или же несла от нее «убытки». Так, в Иране времен шаха Реза Пехлеви основным проводником реформ выступил новый модернизированный, светский средний класс, включавший в себя наемных служащих и лиц свободных профессий. Крестьянство, старый средний класс, в том числе торговцы, оставались приверженцами традиционного образа жизни. Улемы, из-под контроля которых было выведено образование, крестьянство, переживающее трудности, связанные с урбанизацией, старый средний класс, лишившийся ряда привилегий (в том числе экономических), составили социальный базис десекуляризации в Иране. Таким образом, архаизация фактически затронула только небольшую прослойку светской вестернизированной городской среды. Утрата данной социальной группой своего положения привела к отказу от созданных ею социальных парадигм и способов коммуникации [Голдштейн 2012].

\section{Глобализация и трансформации религиозности исламского мира}

Важным фактором, обостряющим весь комплекс причин десекуляризации исламских стран, становится глобализация. Однако влияние глобализации на процессы десекуляризации и исламизации нельзя описать с помощью какой-то одной схемы.

Так, с одной стороны, принято считать, что в массовом сознании мусульман глобализация воспринимается крайне негативно: ее считают средством, прикрывающим стремление правящих кругов развитых стран навязать всему человечеству, и в первую очередь мусульманам, такой мировой порядок, который будет отвечать исключительно их собственным интересам. В результате военные операции в Афганистане, Ираке, Сирии расцениваются не иначе как война против ислама, а иногда в народных кругах и как новый «крестовый поход». Кроме того, проникновение западного образа жизни и универсальной массовой культуры отторгается традиционным мусульманским обществом, рассматривающим их как неприемлемые и уничтожающие культурное разнообразие элементы. Так, П. Дж. Ватикиоти считает, что нестабильность в современном исламском мире является всего лишь «поиском... возможности сосуществования» традиционного образа жизни, «который безвозвратно разрушен, смещен со своих позиций и подавлен», с современностью, «которая наступает со всех сторон» [Vatikiotis 1981: 194]. Проведение в ряде стран антиклерикальных реформ позволило сблизить их с Западом [Алиев 2004: 487].

Рост распространения идей фундаментального ислама является своего рода цивилизационным ответом на распространение западного образа жизни, обострение социального неравенства, неравномерность экономического развития, усугубляемого в процессе глобализации. Исследование Credit Suisse за 2013 г. показывает, что характерной чертой социального неравенства в мире является огромный разрыв между 1 \% элиты, которой принадлежит подавляющее большинство всех ресурсов, и остальной частью населения, которой недоступно подавляющее большинство социальных ресурсов. Так, почти половина населения земного шара обладает всего лишь $1 \%$ ресурсов, в то время как $10 \%$ взрослых граждан обладают $86 \%$, а $1 \%$ из этой группы в той или иной мере контролирует $46 \%$. Деструктивный потенциал неравенства (экономического, социального, национального, территориального, информационного) является реальной основой для соци- 
альной напряженности, представляет угрозу для безопасности личности, общества и государства как на региональном, так и на национальном уровне. При этом в качестве организационной формы, объединяющей протест широких социальных слоев, в настоящее время часто используется воинствующий, радикальный ислам.

Л. Д. Нельсон пишет: «Я вижу немного доказательств того, что процесс "возрождения” религии действительно происходит. Скорее история Ислама доказывает, что эта религия труднее, чем какая-либо другая, приспосабливается к изменениям современного мира. Из-за глобальной политики, а также использования новых технологий Ислам столкнулся с такими проблемами, которые до недавнего времени могло избежать большинство истинных мусульман» [Нельсон 1992: 117].

Формой государственного протеста против диктатуры Запада и непризнания «равноправного» участия в международной жизни сегодня является поддерживаемая, а во многом и насаждаемая официальными властями Анкары исламизация Турции. Альберт Урани отмечает: «...то, что называют возрождением Ислама, до известной степени... является иллюзией: то, что произошло - это не изменение чувств и верований людей, но расширение сферы политических дискуссий и политической деятельности» [Hourani 1981: 189].

Таким образом, с одной стороны, исламское фундаменталистское движение возникает именно как протест против диктатуры глобализма и модернизма. Фундаментализм претендует на роль главного движения протеста, восставшего из глубин истории, способного оградить мир от разрушительных тенденций современной цивилизации. Так, риторика исламистских организаций основывается на пропаганде возвращения к «традиционному» исламу, а именно - исламу времен пророков [Хлопкова, Клементьев 2014: 129-132]. Фундаменталистские идеи, в том числе радикальные, во многом являются следствием секулярных процессов в исламе, порожденных в том числе глобализацией.

С другой же стороны, нельзя отрицать того факта, что фундаментальный ислам противоречит традиционным ценностям тех или иных мусульманских сообществ. Ярким примером здесь может служить Северный Кавказ, для которого традиционными являются местные формы ислама, представляющие собой смешение исламских норм и доисламского адата. Поэтому на Кавказе среди мусульман распространены обычай кровной мести и иные традиции, противоречащие нормам шариата, кавказские женщины никогда не носили одежду, характерную для арабских стран, многоженство в данном регионе не являлось нормой. Проникновение фундаментального ислама на Кавказ, таким образом, является не обращением к традиции, а разрывом с ней, не протестом против модернизации, а ее формой, не традиционалистским ответом на глобализацию, а ее версией.

Исследования Северного Кавказа фиксируют высокий уровень протестных настроений в регионе [см., например: Хайкин, Попов 2012: 14-28]. Вместе с тем политическая и социальная ситуация в Российской Федерации, а также особенности менталитета жителей региона не позволяют канализировать нарастающие протестные настроения в рамки открытого правового механизма. Широкие связи Северо-Кавказского региона с Турцией и арабскими странами, распространенная практика обучения молодежи в исламских университетах за рубежом, активное использование интернет-технологий и иные элементы глобализации способствуют проникновению на Кавказ нетрадиционных форм ислама. В результате именно нетрадиционный ислам становится одним из основных механизмов выражения протестных настроений и социального недовольства против государственной вла- 
сти, коррупции, правового произвола, отсутствия каналов легальной вертикальной мобильности, разложения морали, нарастающего конфликта между поколениями, традиционного уклада жизни [Казенин, Стародубровская]. Таким образом, социальный протест на Северном Кавказе является проводником распространения фундаментального ислама, в том числе радикального.

Разрыв фундаментализма с традицией характерен не только для такого самобытного региона, как Северный Кавказ, но и отчасти для самого арабского мира. Выражаясь в терминологии Э. Хобсбаума, можно констатировать тот факт, что фундаментальным религиозным течениям свойственно «изобретение традиций». Призыв вернуться к традициям означает не возврат к ним, а их замену «новоделом», состоящим из смеси выдуманного и изобретенного вместе с реальными осколками прошлого. Таким образом, конструирование или изобретение традиций приводит к тому, что исламский фундаментализм не имеет ничего общего с реальным традиционным исламом. Данное обстоятельство объясняет парадокс, связанный с тем, что, декларируя борьбу с негативным влиянием Запада, глобализацией, фундаменталистские организации сами активно используют продукты западной цивилизации, в частности информационно-телекоммуникационные сети, в своей деятельности [Клементьев 2010: 28-31].

П. С. Гуревич считает, что подобная двойственность - это основная черта религиозного фундаментализма. «С одной стороны, он позволяет апеллировать к традиции, опираясь на которую можно критически анализировать и осмысливать прогрессистские установки. С другой стороны, он предлагает не столько разматывание назад исторических витков, сколько достижение нового социального идеала. Именно здесь проступает идеологичность фундаментализма. Если традиционализм настаивает на верности традиции, то фундаментализм аранжирует эту традицию в духе новых социальных ориентиров» [Гуревич 1995: 156].

Таким образом, антимодернизм фундаментального ислама одновременно сочетается с модернистскими чертами, а антиглобализм - с его глобалистской природой.

Реакцией на вызовы глобализации стало не только появление исламского фундаментализма, но и изменения в мусульманском сообществе, его приспособление к использованию западных достижений, формирование класса людей, поддерживающих западные ценности [Кузнецов, Салем]. Явление реформизма в исламе призывает к модернизации исламского вероучения вплоть до внедрения западных образцов развития и жизнедеятельности, включая отделение религии от государства [Стародубровская, Соколов 2015: 196].

В этой связи необходимо рассмотреть и возможности секуляризации исламских государств. Нельзя отрицать возможность секуляризации ислама, особенно учитывая опыт Малайзии, Турции и ряда других стран. Действительно, современное исламское духовенство озабочено процессом секуляризации. Среди признаков секуляризации указываются следующие: проявление феномена обрядовой религиозности, потеря религией роли нравственного императива в жизни людей, в межчеловеческих отношениях, утрата семьей роли «домашней религиозной общины», потеря веры в превосходство ислама над другими религиями, в результате чего «принципы ислама перестают быть главными жизненными принципами», а к самому «исламу начинают относиться как к культу, а не как к образу жизни» [Мансуров 2007]. 


\section{Заключение}

В современных условиях невозможно создать общество, не затронутое процессами модернизации и глобализации, поэтому речь идет о том, какое место мусульманский мир может и должен найти в процессах современного глобализирующегося мира. В настоящее время продолжается взаимодействие реформаторства и фундаментализма в исламе, представляющего собой сложный и противоречивый процесс.

Религиозные процессы, происходящие в мусульманском мире, в том числе секуляризация и десекуляризация, имеют определенный внутренний механизм становления и развития, связанный как с особенностями ислама как религии, так и с политическими и экономическими характеристиками конкретных государств. В зависимости от социально-экономических и политических условий религиозность исламских сообществ может трансформироваться как в сторону секуляризации, так и в сторону десекуляризации.

Кроме того, религиозные процессы находятся под сильным внешним воздействием, усугубляемым явлением глобализации. Несмотря на то, что в эпоху глобализации мир стал более открытым, он не стал более справедливым и менее жестоким. Резкие диспропорции в социально-экономическом развитии, агрессивное проникновение западной культуры, нарастание социального недовольства по поводу несовершенств социально-экономической и политической ситуаций локальных сообществ, вызывающих рост протестных настроений, привели к тому, что накопленный негативный потенциал начал реализовываться через модели приспособления к ситуации путем обращения к исламской идентичности, в том числе радикального характера. Призывы к преодолению индивидуализма, бездуховности, отказу от секуляризации, возвращению к духовным ценностям, «традиционным» нормам стали следствием усиления религиозности и консервативных настроений в мусульманских странах.

\section{Литература}

Алиев С. М. История Ирана. ХХ век. М. : ИВ РАН, 2004.

Голдштейн У. Секуляризация и иранская революция [Электронный ресурс] : Неприкосновенный запас. 2012. № 6(86). URL: http://www.nlobooks.ru/node/2943 (дата обращения: 28.04.2017).

Григорьева Л. И. Культ Ошо (Раджнеша) // Религии народов современной России: Словарь / отв. ред. М. П. Мчедлов, Ю. И. Аверьянов, В. Н. Басилов и др. М. : Республика, 2002. С. 186-187.

Гуревич П. Фундаментализм и модернизм как культурные ориентации // Общественные науки и современность. 1995. № 4. С. 154-162.

Казенин К., Стародубровская И. Северный Кавказ: Quo vadis? [Электронный реcypc] : Полит.py. URL: http://polit.ru/article/2014/01/14/caucasus/ (дата обращения: 14.03.2017).

Клементьев А. С. Организационно-правовые аспекты противодействия терроризму в информационной сфере // Вестник Всероссийского института повышения квалификации сотрудников МВД России. 2010. № 1(14). С. 28-31.

Кузнецов В., Салем В. Безальтернативная хрупкость: судьба государства-нации в арабском мире [Электронный ресурс] : Россия в глобальной политике. URL: http:// 
www.globalaffairs.ru/valday/Bezalternativnaya-khrupkost-sudba-gosudarstva-natcii-v-arab skom-mire-18043 (дата обращения: 28.03.2017).

Мансуров С. Секуляризация и ислам [Электронный ресурс] : Арраид. 2007. № 7(66). URL: http://islam.com.ua/gazeta/0704/sekul.shtml (дата обращения: 14.03.2017).

Нельсон Л. Д. Секуляризация и социальная интеграция в сопоставительном аспекте // Социологические исследования. 1992. № 5. С. 111-125.

Сейлова Д. С. Ислам в Казахстане: религиозная идентичность и глобализация [Электронный ресурс] : Ислам в современном мире. 2008. № 12. URL: http://www. idmedina.ru/books/islamic/?508 (дата обращения: 31.03.2017).

Стародубровская И. В., Соколов Д. В. Истоки конфликтов на Северном Кавказе. М. : ИД «Дело» РАНХиГС, 2015.

Угринович Д. М. Теории секуляризации // Современная западная социология. Словарь / сост. Ю. Н. Давыдов. М. : Политиздат, 1990.

Хайкин С. Р., Попов Н. П. Протестные настроения на Северном Кавказе: общее и особенное (часть I) // Мониторинг общественного мнения: экономические и социальные перемены. 2012. № 4(110). С. 14-28.

Хлопкова О. В. Нетрадиционные религиозные верования в контексте западной социально-философской мысли // Вестник Дагестанского государственного университета. 2013а. Вып. 5. С. 218-222.

Хлопкова О. В. Социально-философские аспекты концептуализации религиозности в современной науке: автореф. дис. ... канд. филос. наук. Владимир, 20136.

Хлопкова О. В., Клементьев А. С. Исламский терроризм как форма политического протеста // Сборник материалов V Южно-Российского политологического конвента (Ростов-на-Дону, 20-24 октября 2014 г.) / под ред. И. В. Николаева, Р. А. Пупыкина. Ростов н/Д.: Изд-во Южного федерального ун-та, 2014. С. 129-132.

Crabtree S., Pelham B. Religion Provides Emotional Boost to World's Poor: Gallup.com [сайт]. URL: http://www.gallup.com/poll/116449/Religion-Provides-Emotio nalBoost-World-Poor.aspx (дата обращения: 12.04.2017).

Delamontagne R. G. High Religiosity and Societal Dysfunction in the United States During the First Decade of the Twenty-first Century// Evolutionary Psychology. 2010. Vol. 8(4). Pp. 617-657.

GINI Index (World Bank Estimate) // IBRD IDA [Электронный pecypc]. URL: http://data.worldbank.org/indicator/SI.POV.GINI (дата обращения: 14.04.2017).

Global index of Religiosity and Atheism - 2012 // Wingia.com [сайт]. URL:_http:// www.wingia.com/web/files/richeditor/filemanager/Global_INDEX_of_Religiosity_and_ Atheism_PR_6.pdf (дата обращения: 14.04.2017).

Gregory P. The Chronic Dependence of Popular Religiosity upon Dysfunctional Psychosociological Conditions // Evolutionary Psychology. 2009. Vol. 7(3). Pp. 398-441.

Hourani A. The Emergence of the Middle East. London : Macmillan, 1981.

Inglehart R., Norris P. Sacred and Secular. Religion and Politics Worldwide. Cambridge, 2004 [Электронный ресурс]. URL: http://ksghome.harvard.edu/ pnorris/Books/ Sacred_and_secular.htm (дата обращения: 12.02.2017).

Vatikiotis P. J. Islamic Resurgence: A Critical View // Islam and Power / Ed. by A. S. Cudsi, A. E. Hillal Dessouki. Baltimore : Johns Hopkins University Press, 1981.

Yinger M. J. Sociology Looks at Religion. London, 1963. 